\title{
El acceso a algunas técnicas de reproducción humana asistida: "Crónica de una vida anunciada"*
}

\section{Caridad del Carmen Valdés Díaz**}

\section{RESUMEN}

El acceso a técnicas de reproducción humana asistida en sus diferentes variantes ha estado restringido durante largo tiempo a parejas heterosexuales unidas en matrimonio formalizado o en uniones estables y singulares, y solo como excepción a mujeres solas en casos especiales. Hoy es necesario entender que esas técnicas de procreación no solo actúan como solución terapéutica a problemas de infertilidad, en su sentido tradicional, sino como ejercicio de los derechos sexuales y reproductivos que corresponden a todas las personas, sin discriminación. Se analizan algunos de los problemas que pueden acarrear la práctica de esos procederes encaminados a lograr la procreación médicamente asistida y algunos pronunciamientos jurisprudenciales sobre casos emblemáticos en esta materia.

PALABRAS CLAVE: Reproducción asistida, Fertilización in vitro, Maternidad subrogada, Derechos sexuales y reproductivos, Discriminación, Interés superior del niño.

\begin{abstract}
Access to assisted human reproduction techniques in their different variants has been restricted, for a long time, to heterosexual couples formally married or in stable and singular unions; and only, as exception, to single women in special cases. Today, it is necessary to understand that these procreation techniques not only act as a therapeutic solution to infertility, in its traditional sense; but also as an exercise of sexual and reproductive rights of all individuals, without discrimination. We analyze some of the problems caused by the practice of these procedures directed to achieve medically assisted procreation and some jurisprudential pronouncements on emblematic cases in this matter.
\end{abstract}

KEY WORDS: Assisted reproduction, in vitro fertilization, surrogate motherhood, sexual and reproductive rights, discrimination, the best interests of the child

\footnotetext{
"Artículo recibido el 3 de septiembre de 2016 y aceptado el 30 de octubre de 2016

"* Profesora Titular en la Facultad de Derecho de la Universidad de La Habana, Cuba. cary@lex.uh.cu
} 


\section{SUMARIO}

1. Breve introducción

2. La reproducción médicamente asistida y sus variantes más usuales

3. ¿Solución de un problema de salud o ejercicio de derechos fundamentales?

4. El acceso a técnicas de reproducción humana asistida y la no discriminación

5. La procreación asistida y el interés superior del niño

6. Epílogo

\section{Breve introducción}

Crónica: El día que iba a nacer, lo presintió. Ya su sistema nervioso central estaba formado. Sus sentidos y sus órganos funcionaban. El espacio cálido y húmedo donde su vida se habia desarrollado se hacía pequeño. Su madre biológica habia previsto la fecha de conjunto con los médicos. Sus padres de intención esperaban ansiosos el momento. Pronto dejaría de ser un embrión y se convertiría en persona. Era un niño deseado, amado ya desde su condición de nasciturus, ansiado, previsto, anunciado. ¿Bastaría para desarrollarse como un ser humano pleno, feliz?

La persona, ente sustantivo del derecho (en particular del derecho civil y de familia), es el centro de toda discusión teórica en esta materia y el centro al que irradian las normas protectoras del ser humano. Su atributo esencial es la personalidad jurídica, esa cualidad que dignifica al ser humano y que sirve de base o sustrato para el reconocimiento de su aptitud en cuanto a la titularidad de derechos y obligaciones. No existen disputas en la actualidad en torno al reconocimiento de la personalidad y los derechos inherentes a ella, pero sí acerca del momento a partir del cual debe materializarse en las normas jurídicas ese reconocimiento.

Se ha pretendido dar respuesta a esta inquietud desde diferentes posiciones doctrinales, que han dado lugar a variadas teorías, ${ }^{1}$ desde el derecho romano hasta nuestros días. Nunca ha sido pacífica la cuestión. Arreció la confrontación en la actualidad por la irrupción de las técnicas de reproducción humana asistida y otros adelantos científicos que permiten estudiar, experimentar

\footnotetext{
${ }^{1}$ Clemente Díaz, TiRSo, Derecho Civil, tomo I, La Habana, ENPES, 1983, pp. 202 a 207. Destacan la teoría de la concepción, la teoría del nacimiento, la teoría de la viabilidad, y la teoría ecléctica. Esta última es la teoría más acogida por las legislaciones modernas, especialmente a partir de la codificación decimonónica. En nuestros dias, sin embargo, se aprecia un cierto retorno a la teoria de la concepción, en aras de una protección más cabal al concebido no nacido.
} 
y realizar múltiples procederes en el producto de la concepción, ya sea ésta resultado del natural acoplamiento de hombre y mujer o se haya obtenido con intervención médica dentro o fuera del útero femenino.

El advenimiento de un hijo es muchas veces planificado. Esto es así mucho más en los supuestos de fertilización mediante técnicas de reproducción humana asistida. Desde que los adelantos médicos convirtieron esa última posibilidad en supuestos de utilización relativamente frecuente, el proceso se desarrolló siguiendo un iter preconcebido, un conjunto de pasos establecidos en los cuales inciden requerimientos médicos y legales. Estos últimos no están exentos de la influencia de los avances de la ciencia, sino todo lo contrario, van acompasados al tiempo necesario para que florezca y se sedimente la decisión de la persona o la pareja que acude a su uso luego del conocimiento de la técnica y de sus efectos jurídicos.

La procreación asistida pone en tela de juicio patrones históricamente arraigados respecto a las prácticas reproductivas y las expectativas del nacimiento de los hijos. Se establece de acuerdo con la experiencia a través del coito heterosexual que da lugar a un nuevo ser, heredero cromosómico de ese hombre y esa mujer. Hoy el horizonte se ha ampliado al incluir "la creación de un nuevo ser ajeno al coito parental, al mismo tiempo que, formando parte de una familia, hereda la ajenidad que los bancos de esperma y la congelación de óvulos le autorizan". ${ }^{2}$

El derecho no puede quedar a la saga de tales prácticas. Debe establecer reglas que delimiten aspectos tan sensibles como la filiación de estos niños y niñas que nacen merced la aplicación de estas técnicas, con todo lo que ello trae aparejado: la patria potestad, la responsabilidad parental, la identidad del nacido y sus derechos inherentes a la personalidad. No se deben olvidar, además, los derechos fundamentales de quienes deciden reproducirse a través de estos medios.

Como elemento desencadenante de todos los demás dilemas éticos y jurídicos anteriores resalta, a mi juicio, la regulación del acceso a estas técnicas de reproducción humana asistida. ¿A quiénes se autoriza su uso y en qué casos? ¿Qué técnicas sería lícito utilizar y cuáles no? ¿Debe estar supeditado el acceso a estas técnicas a las posibilidades económicas de quienes pretenden su aplicación? ¿Cómo juega su utilización con el interés superior del niño?

No creo que ninguna respuesta a esas interrogantes pueda considerarse única o definitiva. El derecho, en particular el de familia, debe situarse en la vida social, atender a sus reclamos, ponderar supuestos. No se trata de una

\footnotetext{
${ }^{2}$ Giberti, Eva, Barrios, Gloria, Pachuk, Carlos, Los hijos de la fertilización asistida, Buenos Aires, Sudamericana, 2001, p. 7.
} 
ciencia exacta, no funciona a partir de leyes naturales que existen fuera e independientemente de la voluntad de las personas, ni puede aplicarse siempre con igual rasero, sino por leyes que se crean impregnadas de subjetividad, de concepciones políticas, filosóficas, morales y religiosas. Sin convertir la casuística en el eje cardinal para la interpretación y aplicación de las normas jurídicas, deben elaborarse con abstracción suficiente para que se amolden a casos aparentemente iguales, pero diferentes, porque diferentes son los seres humanos y su situación. Porque la diversidad existe y debe respetarse.

En el entorno jurídico cubano no existe ley que regule la reproducción humana asistida. Sólo hay algunas normas administrativas que no agotan la diversidad de problemas jurídicos que pueden suscitarse. El factor anterior afecta la seguridad jurídica de los sujetos que participan como usuarios de esas técnicas y del profesional de la medicina que las practica, quien puede incurrir en responsabilidad jurídica civil por causar perjuicio a los pacientes o por utilizarlas indebidamente.

Las anteriores cuestiones han motivado la realización de este trabajo. El objetivo es conjeturar en torno a diferentes posiciones a favor o en contra de la aplicación de algunas técnicas de reproducción humana asistida, el acceso a ellas y sus posibles consecuencias o efectos. Para ese propósito, hemos utilizado los métodos de análisis-síntesis, abstracto-concreto y especialmente el de análisis de contenido. Buscamos penetrar el contenido de diferentes materiales escritos (libros, artículos, normas, sentencias) para describir lo explícito en ellos, valorar tendencias, evaluar su claridad, reflejar actitudes y creencias. De esta manera, todo contribuirá a exponer las opiniones propias y ofrecer criterios conclusivos.

\section{La reproducción médicamente asistida y sus variantes más usuales}

La aplicación de técnicas de reproducción asistida en seres humanos ha creado un nuevo espacio de discusión ética y jurídica en cuanto a sus implicaciones en el derecho. Si bien han sido objeto de investigación desde el siglo XVIII (el primer resultado positivo de su utilización lo obtuvo John Hunter, en Inglaterra), ${ }^{3}$

\footnotetext{
${ }^{3}$ La primera inseminación exitosa en humanos ha sido atribuida a diferentes investigadores. En la última década del siglo XVIII, John Hunter hizo su célebre experiencia en el caso de un hombre con hipospadias. Según referencias, el procedimiento consistió en recoger el semen emitido durante el coito que había sido efectuado y, con una jeringuilla especial, inyectarlo profundamente en la vagina. Aunque Hunter guardó el secreto, su sobrino Eduardo Home lo informó a la muerte de aquél en 1793. Señaló que el embarazo y el parto fueron normales. Se registran otros antecedentes más remotos de la aplicación de estas técnicas en seres humanos, como el caso de la segunda esposa de Enrique IV de Castilla, Juana de Portugal, que fue inseminada por el famoso médico Villenueve. Sin embargo, se
} 
es desde la segunda mitad del siglo xx que han cobrado mayor auge.

Dado el desarrollo científico alcanzado en este campo, se utilizan diferentes variantes de esas técnicas en la actualidad. Dentro de ellas pueden mencionarse la inseminación artificial homóloga (IAH), la heteróloga (IAD) e intraperitoneal (IAI); fecundación in vitro, con transplantes de embriones (FIVTE); transferencia intrauterina de gametos (TIG), transferencia de cigotos (preembriones en los primeros estadios de la fecundación) a las trompas de Falopio (ZIFT, por sus siglas en inglés), transferencia de embriones a las trompas de Falopio en estadios más avanzados de desarrollo (TET); inyección intracitoplasmática (ICSI), la transferencia de pronúcleos a las trompas de Falopio (Prost), la colocación de ovocitos y espermatozoides en el útero (Toast) y la maternidad subrogada. En este trabajo solo nos referiremos, como ya se apuntó, a algunas de esas técnicas: la inseminación artificial, por su primacía y la extensión de su uso; la fertilización in vitro, porque es la base de otras modalidades más específicas; y la maternidad subrogada, por ser de las más polémicas, y la que genera más reparos en cuanto a su utilización.

La inseminación artificial es la principal técnica de fecundación in vivo. Consiste en colocar en el interior del útero o del canal cervical de la mujer el semen del varón previamente preparado. Para ello, es preciso realizar la monitorización de un ciclo menstrual con el fin de detectar el momento de la ovulación. Este procedimiento se utiliza en los programas de reproducción asistida como la primera alternativa de la pareja que sufre la patología de la infertilidad, sin haber logrado un embarazo tras la aplicación de tratamientos convencionales. Tiene el objetivo de asegurar la existencia de óvulos disponibles, acercar los espermatozoides al óvulo en el aparato genital femenino y mejorar e incrementar el potencial de fertilidad de los espermatozoides.

La inseminación artificial permite conseguir el embarazo en aquellos casos en los cuales el semen no reúne todas las condiciones necesarias para la fecundación del óvulo. Se emplea también cuando el varón padece alguna patología que impide depositar el semen normalmente en la vagina. En la actualidad, se utiliza a veces para contar de antemano con material genético en casos en que el varón deba ser sometido a tratamientos de quimioterapia o radioterapia, en los cuales se pueda prever la alteración de las células germinales productoras de espermatozoides, o cuando las características del eyaculado prevean una mala eficacia fertilizante.

dice que el intento fue fallido. Guzmán Ávalos, Anibal, Inseminación artificial y fecundación in vitro humanas. Un nuevo modo de filiación, México, Biblioteca Universidad Veracruzana, 2001, p. 28. 
Por su parte, Cárcaba Fernández define fertilización in vitro como "la unión del espermatozoide y del óvulo en un laboratorio, creando un cigoto que tras la división celular adquiere el status embrionario siendo transferido al útero de su madre antes del decimocuarto día a contar desde la fecundación, y descontando el tiempo que pudo estar crioconservado". ${ }^{4}$

Generalmente se aplica para posibilitar una maternidad en casos de obstrucción o ausencia de las trompas de Falopio; también se emplea en hipótesis de esterilidad masculina. Aquí, tanto la fertilización como los primeros estadios del desarrollo embrionario se efectúan dentro de un medio de cultivo ubicado en un lugar diseñado específicamente para ello. Esto permite poner en contacto directo a los gametos femeninos y masculinos, facilitando su encuentro. Después de terminado el proceso, se transfieren al útero materno los embriones obtenidos para que puedan continuar su desarrollo, como sucede en la fertilización natural. Su práctica exige la extracción y fecundación de un número considerable de óvulos, de los cuales son transportados a la mujer aproximadamente cuatro, con el objetivo fundamental de evitar embarazos múltiples. Sin embargo, no se puede controlar el destino de los restantes, razón por la cual ha encontrado muchos oponentes.

Tanto la inseminación in vivo como la fertilización in vitro pueden ser homólogas o heterólogas, dependiendo de si se llevan a efecto con material genético de un miembro de la pareja o aportado por una tercera persona ajena a ella. La variante más aceptada es la homóloga, que enfrenta menores implicaciones legales de conflicto. La segunda es propicia para que surjan dilemas relativos a la filiación del hijo nacido, como resultado de la utilización del semen de un hombre que no es la pareja de su madre, o con material reproductivo de una mujer ajena a la pareja. Implica además la existencia de los bancos de esperma, los cuales encarecen el procedimiento, pero son considerados vitales para este tipo de fecundación.

También puede utilizarse la controvertida figura de la maternidad sustituta o subrogada. Se trata de un procedimiento que permite que una mujer ajena a quien tiene la voluntad procreacional desarrolle el embarazo, realice el parto y entregue luego al recién nacido. Hasta hace poco, se aplicaba únicamente cuando la mujer que tenía el propósito de ser madre era infértil o cuando producía óvulos pero no podía gestar. Como más adelante se verá, hoy también es la vía que utilizan parejas homosexuales masculinas para materializar su deseo de ser padres.

\footnotetext{
${ }^{4}$ Cárcaba Fernández, Maria, los problemas juridicos planteados por las nuevas técnicas de procreación humana, Barcelona, José Maria Bosch, 1995, pp.137 y ss.
} 
De los procederes mencionados, en Cuba sólo se emplea hasta el momento la inseminación artificial en sus dos variantes (homóloga y heteróloga) pues la fecundación artificial in vitro requiere procederes muy costosos, laboratorios confiables, bancos de semen con óptimas condiciones, de los cuales no se dispone actualmente. No se cuenta con ninguna ley especial para su aplicación, solo normas administrativas del Ministerio de Salud Pública que regulan dos aspectos esenciales: la edad de la mujer para acceder a esas técnicas (entre 20 y 35 años) y su estado conyugal, a fin de obtener o no el consentimiento informado del esposo.

La maternidad se determina en todo caso por el hecho del parto; la determinación de la paternidad del menor concebido por inseminación homóloga no generaría conflictos, pues la identidad entre el padre genético (quien aporta el semen) y el padre legal o jurídico (quien ostenta de hecho el estado de padre) coincide por tratarse de la misma persona. La inscripción del nacido se practica conforme con el artículo 45 de la Ley del Registro del Estado Civil. Pero si el menor es fruto de una inseminación heteróloga, a pesar de que el artículo 74 del Código de Familia establece que son hijos de las personas unidas en matrimonio los nacidos durante la vida matrimonial y en este sentido la filiación del menor sería con su padre jurídico (miembro de la pareja), el donante de semen puede estimarse con derecho a la paternidad del menor y reclamarla conforme a lo establecido en el artículo 81 del Código de Familia. No obstante, hasta el presente no se han entablado procesos legales sobre cuestiones de esta naturaleza. ${ }^{5}$

\footnotetext{
${ }^{5}$ Como consecuencia de la aparición y aplicación relativamente frecuente de técnicas de reproducción humana asistida y de otras muchas realidades que al derecho toca tutelar han tomado auge ciertas disciplinas como la bioética y el bioderecho. La bioética es el estudio interdisciplinario del conjunto de condiciones que exige una gestión responsable de la vida humana o de la persona en el marco de los rápidos y complejos progresos del saber y de las tecnologías biomédicas. Por su parte, el bioderecho se ocupa del conjunto de materias vivas consideradas

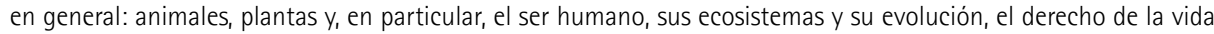
desde el comienzo de la existencia, desarrollo y final del ciclo vital del ser humano; la procreación humana asistida con la inseminación artificial y la fertilización in vitro con transferencia de embriones.
} 


\section{3. ¿Solución de un problema de salud o ejercicio de derechos fundamentales?}

La infertilidad o esterilidad de la pareja ${ }^{6}$ es entendida, en general, como la incapacidad para tener hijos. Puede ser primaria, si se trata de una pareja que nunca ha logrado embarazos; o secundaria, cuando han logrado embarazos anteriormente, pero en tiempo presente no lo consiguen. Ha sido considerada por la Organización Mundial de la Salud como una enfermedad del sistema reproductivo que afecta la salud de las personas que la sufren. Esta enfermedad no involucra gravemente la vida ni, necesariamente, la dignidad o a la integridad personal. Sin embargo, es un aspecto determinante de la condición general de la salud y sí puede interferir negativamente en otras dimensiones vitales cuando la paternidad/maternidad hace parte del proyecto de vida de la persona o la pareja.

En mayor o menor proporción, la infertilidad afecta a un número considerable de personas en todo el mundo. Diferentes índices indirectos de infertilidad sugieren que alrededor de 10\% de las parejas sufren este trastorno de la reproducción. En algunos países la frecuencia puede ser más baja (5\%); en otros, más alta (15\%). En Cuba, los estudios realizados sobre la infertilidad sólo abarcan a las parejas que acuden a los hospitales. Por esta razón, no existen datos ciertos sobre la prevalencia de la infertilidad en la población. Se presume que comprende de 10 a 12\% de las personas en edad reproductiva.

En las últimas décadas, el vertiginoso avance de las ciencias médica y biológica ha permitido perfeccionar las técnicas de diagnóstico de la infertilidad. Paralelamente a ello, su solución terapéutica depende de las causas que la motivan. Las técnicas de reproducción humana asistida se aplican con gran éxito, además permiten la prevención y tratamiento de enfermedades de origen genético o hereditario y la investigación con gametos u óvulos fecundados humanos.

Hasta hace relativamente poco tiempo, las técnicas de reproducción humana asistida eran consideradas únicamente como terapéutica a la esterilidad, entendida como un problema de salud. En las últimas décadas se han asociado también a la autonomía personal y al ejercicio de derechos sexuales y reproductivos.

\footnotetext{
${ }^{6}$ Algunos autores entienden que debe distinguirse la infertilidad de la esterilidad. Esta última es la que verdaderamente constituye una discapacidad definitiva o irreversible para concebir. No obstante, se admite que en algunos casos puede corregirse mediante la utilización de procedimientos médico quirúrgicos. La infertilidad, por su parte, permite concebir pero no lograr la viabilidad del producto de la concepción. Guzmán Ávalos, Anibal, Inseminación artificial y fecundación in vitro humanas. Un nuevo modo de filiación, México, Biblioteca Universidad Veracruzana, 2001, p. 20. Sin embargo, los términos se utilizan indistintamente: ambos implican la imposibilidad de tener descendencia.
} 
Actualmente, algunos consideran a los derechos sexuales y reproductivos como derechos humanos, ${ }^{7}$ que incluyen el derecho de toda persona a vivir y tener control sobre su sexualidad. Tienen por base los principios de autonomía, igualdad y diversidad, así como la integridad corporal. Su reconocimiento como derechos inseparables de la condición de persona no ha implicado su inmediata incorporación a los derechos fundamentales consagrados en las Constituciones, ni tampoco al elenco de los derechos inherentes a la personalidad, usualmente enumerados en las normas civiles. Pero así debe ocurrir, en tanto son derechos inalienables vinculados esencialmente al ser humano; constituyen una legítima expectativa de respeto a su dignidad. ${ }^{8}$

Estos derechos se vinculan e interrelacionan, aunque no se identifican plenamente. Hoy en día, tanto sexualidad como reproducción se encuentran comprendidas en una concepción integral de la salud. De una parte, es indiscutible que la esfera sexual constituye un factor determinante en el desarrollo de la personalidad. Como tal, es parte de la dignidad de todo individuo; no es una dimensión secundaria de la vida humana; pertenece íntimamente a su constitución. Toda persona tiene derecho a vivir plenamente con entera libertad, con el normal acotamiento que establecen las leyes, tomando en cuenta la moral social imperante y con el valladar individual que establece cada quien. Los derechos sexuales atribuyen una situación jurídica de poder a la persona para que pueda vivir y tener control sobre su sexualidad, incluyendo la posibilidad de pedir y obtener información sobre estos temas, así como sobre los cuidados preventivos y curativos necesarios para mantener la salud en esta esfera.

En estrecha comunión con lo anterior, las personas tienen derecho a decidir en sentido positivo o negativo sobre su reproducción. Es decir, pueden tomar partido respecto a ellas mismas sobre la aplicación de medidas de anticoncepción o contracepción, tratamientos seguros para fertilidad, infertilidad, información actualizada sobre medicamentos, tecnologías y tratamientos médicos, en función de la procreación, incluyendo las técnicas procreación asistida en cualquiera de sus variantes. La titularidad de este derecho no distingue, o no debe distinguir, entre sexos, géneros, razas o aptitudes de cualquier naturaleza. No vale discriminación de ningún tipo; debe reconocerse a todos por igual.

\footnotetext{
${ }^{7}$ Su incorporación al elenco de derechos humanos es relativamente reciente y no totalmente expresa en cuanto a tal denominación. Se remonta a la Conferencia de Naciones Unidas sobre Derechos Humanos, celebrada en Viena en 1993, la Conferencia sobre Población y Desarrollo, celebrada en El Cairo en 1994, y la Conferencia Internacional sobre la Mujer, realizada en Beijing, en 1995.

${ }^{8}$ MinYerSkY, Nelly, "Derechos sexuales y reproductivos: el aborto legal y seguro", en Aída Kemelmajer de Carlucci y Leonardo B. Pérez Gallardo (coords.), Nuevos perfiles del derecho de familia, Buenos Aires, Rubinzal Culzoni, 2006, pp. 139 y ss.
} 
Sin embargo, el derecho a la procreación no es ilimitado, como no lo es ningún derecho subjetivo. Su límite esencial está en el derecho de los demás, especialmente en los potenciales derechos del niño por procrear. Deben ejercitarse con plena responsabilidad, porque en su ejercicio hay un límite natural, que es el propio resultado de su práctica: la procreación de nuevos seres humanos. ${ }^{9}$

Por otra parte, los tribunales internacionales de derechos humanos han hecho una interpretación amplia del derecho a la vida privada, como abarcador de una serie de factores relacionados con la dignidad del individuo, como expresión del libre desarrollo de su personalidad. En ella, incluyen la decisión de fundar una familia, de ser o no madre o padre, ya sea de forma genética o biológica, mediante el apareamiento sexual o mediante la aplicación de técnicas de reproducción asistida, desvinculadas del sexo. Subsumen también el derecho a disfrutar de los adelantos científicos y tecnológicos, así como adquirir la condición de madre o padre sin que exista vínculo genético con el producto de la concepción a través de una manifestación de voluntad procreacional. Además, entienden la infertilidad como una discapacidad para procrear. Negar a las personas que la padecen el acceso a técnicas de reproducción médicamente asistida sería discriminatorio y atentaría contra los postulados de la Convención Internacional de las Personas con Discapacidad y otros instrumentos internacionales, según ha hecho notar en nuestra región la Corte Interamericana de Derechos Humanos. ${ }^{10}$

Todo lo anterior resulta de significativa importancia para precisar quiénes deben tener acceso a las técnicas de reproducción humana asistida. Si sólo se aprecian como paliativo a un problema de salud, es claro que únicamente las parejas heterosexuales y las personas solteras aquejadas de tal discapacidad reproductiva, previamente diagnosticadas, podrían utilizarlas. Si las consideramos como integrantes de los derechos sexuales y reproductivos que permiten decidir cuándo y cómo reproducirse, y del derecho a la vida privada y familiar que tiene toda persona, como parece más razonable y a tono con la evolución social actual, se podría acceder a ellas con independencia de cualquier patología o diagnóstico, sin que sea relevante la orientación sexual de las personas o parejas que decidan optar por ellas.

\footnotetext{
${ }^{9}$ Algunas voces disidentes del reconocimiento de estos derechos, en particular de que incluyan el acceso a técnicas de reproducción humana asistida, señalan que las conferencias internacionales del Cairo y Pekin son instrumentos sin carácter vinculante, pues no son tratados ni convenciones internacionales, sino únicamente conferencias especializadas internacionales cuyas resoluciones carecen de carácter obligatorio.

${ }^{10} \mathrm{CIDH}_{1}$ "Artavia Murrillo y otros vs. Costa Rica". Disponible en: http://www.corteidh.or.cr/docs/casos/articulos/seriec_257_esp.pdf
} 


\section{El acceso a técnicas de reproducción humana asistida y la no discriminación}

El principio de no discriminación debe ser la brújula para regular legalmente el acceso a técnicas de reproducción humana asistida. Digo regular, no determinar. Las normas pueden establecer reglas, pero si no son adecuadas al tiempo que se vive ni responden a las expectativas de sus destinatarios, difícilmente cúmplanse cumplirán. Por eso creo que la regulación debe ser amplia, abarcadora y no discriminatoria. Debe servir de ropaje legal a los procederes de la procreación asistida.

Las primeras normas sobre técnicas de reproducción humana asistida preveían el acceso sólo a personas con capacidad suficiente, unidas en matrimonio heterosexual formalizado. Luego se extendió a mujeres solas, en supuestos excepcionales. Con la propagación y reconocimiento que paulatinamente han alcanzado las uniones de hecho, se reguló, no sin ciertas reticencias, el acceso de mujeres y hombres unidos de esta forma. En el siglo xxI, bajo el influjo de los movimientos de lesbianas, gays, bisexuales, transexuales, travestis y transgéneros, identificados con las siglas LGBT, en algunos ordenamientos jurídicos ha comenzado a admitirse la aplicación de esas técnicas a personas homosexuales y parejas del mismo sexo, que previamente habían conquistado el derecho a contraer matrimonio igualitario o reconocimientos legales de sus uniones. Empero, dada la perspectiva mayoritaria de rechazo a la maternidad subrogada, los homosexuales masculinos ven impedida la opción de tener hijos vinculados con ellos biológicamente. Esto se considera contrario al principio de igualdad y no discriminación de las personas.

No sólo en casos de personas o parejas homosexuales se ha entendido presente la discriminación, también en casos de heterosexuales con determinadas enfermedades, o sin medios económicos para pagar los costos de la reproducción asistida, o por valladares legales impuestos a algunas de estas técnicas. Si se trata de mujeres solas, amén del rechazo que pudieran sufrir en algunas sociedades, considero que están en su derecho de decidir respecto a la maternidad, en sentido positivo o negativo, siempre con responsabilidad y tomando en cuenta el interés superior del niño.

La decisión de la mujer de enfrentar sola la maternidad es una de las vías que conduce a la constitución de las familias monoparentales, ${ }^{11}$ reconocidas

\footnotetext{
11 Definidas como aquellas que están formadas por el padre o la madre con sus hijos, con independencia de que estos sean adoptados, fruto de una relación matrimonial anterior o hayan sido concebidos fuera del matrimonio. Su rasgo básico es que la responsabilidad del hogar recae sobre una sola persona, la mayoria de las veces una mujer.
} 
hoy por el derecho en casi todas las latitudes con iguales derechos a las clásicas biparentales. ${ }^{12}$ La maternidad en solitario, cuando provenía de una decisión autónoma de la mujer, sufría el rechazo social y, consecuentemente, del derecho. Los hijos habidos fuera de matrimonio eran considerados ilegítimos y tenían una posición inferior.

La ampliación de la base social de procedencia de las mujeres que afrontan solas su maternidad, cada vez más formadas e independientes en el orden económico y personal, ha eliminado el estigma de marginalidad de las familias monoparentales. Así, la presencia amplia y activa de la mujer en el mercado del trabajo y su independencia económica, ha favorecido la toma de decisiones en cuanto a su vida personal y familiar. De igual modo, hoy el principio de igualdad consagrado en casi todas las Constituciones exige el reconocimiento de la igualdad de los hijos, con independencia de su filiación matrimonial o no. Se ha superado cualquier discriminación en este orden.

Como ya se apuntó, la fertilización in vitro es un procedimiento mediante el cual los óvulos son removidos de los ovarios para inseminarlos con esperma en un laboratorio. Se observa el proceso de fecundación e incubación de los embriones y finalmente se transfieren al útero materno. El rechazo fundamental que se argumenta en contra de su utilización es la necesidad de obtener varios embriones para garantizar el éxito de la técnica. Por consiguiente, resulta incierto el destino de aquellos que no se implantan en el útero de la madre, que podrán ser objeto de investigación, manipulación o destrucción, lo cual se ha entendido como un atentado a la vida humana, violatorio del derecho fundamental esencial: la vida misma. ${ }^{13}$ En este sentido, la cuestión de asumir cuándo comienza la vida humana y cuándo se es persona para el derecho resulta trascendental.

En general, las Constituciones nacionales han establecido normas protectoras del derecho a la vida de amplio alcance. Sus interpretaciones han conducido a considerar que las reglas sobre ese derecho alcanzan a proteger jurídicamente a los embriones y a los fetos. Por ende, si los fetos o embriones son titulares del derecho a la vida, no se justifica bajo ninguna circunstancia el establecimiento de reglas que permitan interrumpir un embarazo. En caso

Vela Sánchez, Antonio, Las familias monoparentales, Granada, Comares, 2005, p. 9.

12 Familia conformada por un núcleo que tiene su base en el matrimonio, a partir del cual se cumple la función reproductora y se comparten las responsabilidades del hogar. La definición se extiende hoy a las familias que tienen como base una pareja estable y singular, aunque no esté casada. Vela Sánchez, Antonio, Las familias monoparentales, Granada, Comares, 2005, p. 5.

${ }^{13}$ Mateo de Acosta, Osvaldo y Andino Valdés, Nidia, "Fertilización in vitro (Fiv) y transferencia de embriones (te) en el humano. Consideraciones éticas, científicas y utilidad", Revista Cubana Médica, No. 24, agosto, 1985. 
de utilización de técnicas de reproducción humana asistida, no es admisible la destrucción de embriones, pues se conculcaría injustificadamente el derecho a la vida. Esta posición se pone hoy en entredicho.

En apoyo a la posición anterior, señalan Zárate-Cuello y Celis, ${ }^{14}$ refiriéndose a la legislación española sobre este tema, que la creación de biobancos, producto de embriones supernumerarios o sobrantes de la fertilización in vitro, genera desafíos al bioderecho. Entre ellos, se cuenta crear vida en el laboratorio para luego destruirla con el paradigma del beneficio de la ciencia. Añaden que los embriones supernumerarios, creados ex profeso para obtener células troncales o células madre, están para investigaciones en medicina regenerativa, la experimentación con fines de investigación y la clonación terapéutica.

Ante estos tópicos, el embrión es el protagonista de la violencia prenatal. Zárate-Cuello define esta última como: "situaciones de riesgo y peligro en que se encuentra el ser humano en sus fases primigenias de desarrollo, cuando es sometido al diagnóstico genético preimplantatorio (DGP), selección embrionaria, reducción embrionaria y finalmente su congelación, como producto sobrante de las técnicas de fecundación in vitro. Es decir, la vida cosificada, discriminada, manipulada, seleccionada, desechada, destruida y congelada injustamente, suspendida en nitrógeno líquido". ${ }^{15}$

Indudablemente, la vida humana es valiosa per se, desde sus orígenes y hasta su conclusión. Sin aditamentos o requisitos constituye el más preciado bien jurídico. La dignidad humana, como término ontológico, es el fundamento esencial y legitimador de la protección que el derecho dispensa a todas las personas, incluso durante la etapa anterior al nacimiento. ${ }^{16}$ No obstante, cuando se habla del nasciturus (concebido no nacido), se hace alusión al ente humano entendido como el producto de la concepción, en el período entre la fecundación hasta el instante anterior a su separación definitiva del útero materno. Esto incluye tanto la fase inicial embrionaria como el estadio fetal que prosigue, hasta llegar al alumbramiento.

El concepto jurídico de persona, por su parte, se presenta vinculado con el hecho del nacimiento. Su existencia presupone el establecimiento de vínculos

\footnotetext{
14 Zárate-Cuello, Amparo y Celis, Luis Gustavo, "Implicaciones bioéticas derivadas del acceso de las parejas del mismo sexo a las tecnologías provenientes de la biomedicina y la biotecnología, para la conformación de familias homoparentales", Revista Persona y Bioética, vol. 19, No. 1, 2015, pp. 48-63.

${ }_{15}$ Zárate Cuello, Amparo, Biomedicina y biotecnología ante la violencia prenatal (Legislación comparada con el derecho español), Colombia, Lid Editorial Colombia SAS - Ediciones de la U, 2014, p. 257.

${ }^{16}$ Valdés Diaz, CARIDAd del CARMen, "Del derecho a la vida y los derechos sexuales y reproductivos, ¿configuración armónica o lucha de contrarios?", Ius, Revista del Instituto de Ciencias Jurídicas de Puebla, nueva época, año 5, julio-diciembre 2012, p. 225.
} 
determinados que exceden su ámbito único o individual para conectarse con las demás personas que integran la organización social. Por ello, antes del nacimiento no es posible hablar de persona en sentido jurídico, pues el concebido no se vincula con el exterior per se, sino exclusivamente a través de la madre. ${ }^{17}$ Así, el embrión depende biológicamente de la mujer que lo porta en su útero o del mantenimiento de condiciones especiales, en caso del embrión in vitro. No es persona y por tanto no está dotado de personalidad jurídica; pero tampoco puede considerarse una simple cosa o bien, pues, sin duda, el embrión humano merece particular consideración. Su estatus en el derecho tiene naturaleza especial.

En esa línea de pensamiento, Bonilla Sánchez ${ }^{18}$ afirma: "El nasciturus, al carecer de los requisitos del artículo 30 del Código Civil [español], no es titular de los derechos fundamentales, aunque su vida y su seguridad sean bienes jurídicos protegidos constitucionalmente, por lo que se rechaza la posibilidad del aborto libre y sólo se despenalizan determinados supuestos de interrupción voluntaria del embarazo". Añade que, respecto al nasciturus, la vida humana se entiende como un proceso biológico previo al nacimiento. Es sólo un bien constitucionalmente protegido, pero su portador, sea embrión o feto, no es titular de derechos fundamentales.

Castiella Rodríguez, por su parte, sostiene que la cualidad de lo personal no es resultado de un desarrollo, sino la estructura característica de un desarrollo que mantiene unidad a través del tiempo. Por ello, considera válida, útil e ilustrativa una nueva categoría que se suma a las clásicas en materia de persona, en sede civil: la personeidad. La personalidad, al decir de Zubiri, ${ }^{19}$ alude a la figura que resulta de la realidad humana en sí misma durante su ciclo de vida. Constituye no un punto de partida sino un término progresivo del desarrollo vital que experimenta el ser humano. La personeidad, en tanto, implica el carácter estructural de la persona como punto de partida de su desarrollo. Precede a la existencia misma de la personalidad.

La Corte Interamericana de Derechos Humanos, en el controvertido caso Artavia Murillo vs. Costa Rica, que versó sobre el uso de la fertilización in vitro en parejas infértiles, consideró que el feto no es un sujeto de derecho. Para llegar a tal conclusión, subyace la tesis de que los derechos sólo pueden ser ejercitados por personas, ya que únicamente éstas pueden ser las beneficiarias

\footnotetext{
${ }_{17}$ Planiol, Marcel, Tratado elemental de derecho civil, vol. III, México, Cajica, 1946, p. 195.

${ }^{18}$ Bonilla Sánchez, Juan José, Personas y derechos de la personalidad, Madrid, Reus, 2010, p. 234.

${ }^{19}$ Castiella Rodriguez, José, "La persona, el estado civil y el registro civil. Primera Parte. La persona en general", en Juan Delgado de Miguel (coord.), Instituciones de derecho privado, tomo I, vol. 2, Madrid, Civitas, 2003, pp. 19-20.
} 
de la normatividad que otorgan los principios constitucionales que adscriben derechos. Siendo ello así, el nonato no está legitimado para el ejercicio de derechos en forma autónoma, como sí lo están las personas nacidas y completas.

La Corte llegó a las siguientes conclusiones en su labor interpretativa. En primer lugar, afirma "que el embrión no puede ser entendido como persona para efectos del artículo 4.1 de la Convención Americana”. En segundo lugar, distingue "concepción" de "fertilización"; sostiene que "la 'concepción' en el sentido del artículo 4.1 tiene lugar desde el momento en que el embrión se implanta en el útero"; por lo tanto, la Convención no es aplicable antes de este evento. En tercer lugar, afirma que, de acuerdo con la expresión "en general", la protección del derecho a la vida no puede ser absoluta, "sino es gradual e incremental según su desarrollo, debido a que no constituye un deber absoluto e incondicional". Finalmente, afirma que "el objeto directo de protección [del artículo 4.1] es fundamentalmente la mujer embarazada”.

La sentencia ha sido atacada por transgredir el margen de discrecionalidad de los Estados para establecer sus normas internas en aspectos tan controvertidos como la aplicación de técnicas de reproducción humana asistida y la determinación del ámbito de protección de la vida. Según el artículo 4.1 del Pacto de San José, la vida debe comenzar, en general, desde la concepción. Entiendo, por mi parte, que la sentencia no ha sido contraria a la letra del precepto, pues la Corte no niega protección a la vida desde la concepción, sólo que, a su juicio, la concepción, cuando de fertilización in vitro se trata, comienza realmente cuando el embrión se transfiere al útero materno. Como afirma Kemelmajer de Carlucci, ${ }^{20}$ si bien la vida potencial empieza desde la concepción, la cuestión por debatir seriamente es qué sucede con esa vida potencial cuando entra en conflicto con derechos fundamentales de personas que viven ya, ahora.

Aunque la decisión de la Corte Interamericana de Derechos Humanos es altamente polémica donde no existe un consenso moral ni político, el derecho constitucional comparado había ido construyendo de forma progresiva un marco normativo jurídicamente justificativo respecto a la no-titularidad del feto para ejercer derechos básicos. Así, como ejemplo puede observarse el fallo de la Corte Constitucional de Colombia. En su sentencia C-355/2006 efectuó una distinción entre la vida como un bien (moral), y la vida como bien jurídico (en lenguaje de derechos subjetivos) como la exigencia (a particulares y al Es-

\footnotetext{
${ }^{20}$ Kemelmajer de Carluccl, Aida, El derecho humano a la vida intima de la mujer embarazada, el riesgo grave para su salud y el principio de igualdad frente a los casos de no punibilidad en la jurisprudencia del Tribunal Europeo de Derechos Humanos, Argentina, Fondo Editorial La Ley - Academia Nacional de Derecho y Ciencias Sociales de Buenos Aires, 2007, p. 16.
} 
tado) de no privar arbitraria o injustificadamente a un sujeto del disfrute de los fenómenos de la existencia humana.

La vida tiene diferentes tratamientos normativos, pudiendo distinguirse el derecho a la vida consagrado en el artículo 11 constitucional, de la vida como bien jurídico protegido por la Constitución. El derecho a la vida supone la titularidad para su ejercicio y dicha titularidad, como la de todos los derechos está restringida a la persona humana, mientras que la protección de la vida se predica incluso respecto de quienes no han alcanzado esta condición.

En términos muy similares, también efectuando una negación de la calidad de sujeto de derecho al feto, el Tribunal Constitucional español, en su sentencia número 53 de 1985, sostuvo: "los argumentos aducidos por los recurrentes no pueden estimarse para fundamentar la tesis de que al nasciturus le corresponda también la titularidad del derecho a la vida". ${ }^{21}$

El Tribunal Europeo de Derechos Humanos, por su parte, también ha dictado sentencias emblemáticas en estos temas. Pero el silencio de la Convención Europea de Derechos Humanos respecto a la protección de la vida del embrión, junto con otras consideraciones en torno al consenso, permiten un amplio margen de discrecionalidad a los Estados parte, que decidirán cómo legislar sobre materias como la interrupción del embarazo, las técnicas de fertilización in vitro o el diagnóstico preimplantacional, pero sin lesionar derechos fundamentales de las personas. ${ }^{22}$

Así, por ejemplo, en S.H. y otros vs. Austria, el Tribunal declaró como compatible con el Convenio Europeo de Derechos Humanos la prohibición de la fertilización in vitro heteróloga, con espermatozoides y óvulos de terceros. Esta variante de dicho proceder no es admitida en algunos Estados, por considerarse que (además del problema de los embriones sobrantes) atenta contra la identidad del niño. Expresamente, el alto Tribunal señaló que existe un margen de apreciación estatal en materias con importantes controversias sobre asuntos morales y éticos, tal como el debate sobre las técnicas de reproducción asistida. Empero, falló declarando que la negativa a una pareja de acceder a la fertilización in vitro es una injerencia en su vida privada y familiar que además conduce a trato discriminatorio.

\footnotetext{
${ }^{21}$ Chía, Eduardo y Contreras, Pablo, "Análisis de la sentencia Artavia Murillo y otros (fecundación In Vitro) vs. Costa Rica de la Corte Interamericana de Derechos Humanos", Estudios Constitucionales, vol. 12, No. 1, Santiago de Chile, 2014. Disponible en http://dx.doi.org/10.4067/S0718-52002014000100015

${ }^{22}$ Chí, Eduardo y Contreras, Pablo, "Análisis de la sentencia Artavia Murillo y otros (fecundación In Vitro) vs. Costa Rica de la Corte Interamericana de Derechos Humanos", Estudios Constitucionales, vol. 12, No. 1, Santiago de Chile, 2014. Disponible en http://dx.doi.org/10.4067/S0718-52002014000100015
} 
El Tribunal señaló que la prohibición absoluta de la donación de óvulos impuesta por la ley austriaca lacera los derechos de la pareja de acuerdo con los artículos 14 y 8 del Convenio, porque daba lugar a una disparidad de tratamiento desproporcionado entre los pacientes que podían acudir a la inseminación artificial y los que, exclusivamente, podían utilizar la fecundación in vitro. La ley austriaca, de manera injustificada, admitía algunos tratamientos heterólogos y proscribía otros, vulnerando así el principio de igualdad. Cuando un ordenamiento, en el ejercicio de sus poderes autónomos, decide regular un hecho jurídicamente relevante, debe hacerlo de manera racional y coherente, sin penalizar a sujetos que no pueden acceder a tratamientos sanitarios. La desproporción resultaba de la circunstancia de que se permitía la fecundación artificial heteróloga con gametos masculinos y, en cambio, no con gametos femeninos, la cual planteaba los mismos problemas desde el punto de vista social, moral y jurídico. De hecho, en ninguno de los dos casos los hijos presentan los rasgos genéticos de uno de los progenitores, creándose, no obstante, relaciones jurídicas con ambos. ${ }^{23}$

En el caso Costa y Pavan vs. Italia, el Tribunal Europeo de Derechos Humanos se pronunció, en su sentencia de 28 de agosto de 2012, a favor de las técnicas de reproducción humana asistida para realizar diagnóstico preimplantatorio. A dos cónyuges italianos, portadores sanos de fibrosis cística, después de haber generado naturalmente un hijo enfermo y de haberse sometido la mujer a un aborto terapéutico (con ocasión de otro embarazo en el cual se detectó que el feto padecía la enfermedad), se les denegó la posibilidad de acceder a las técnicas de reproducción asistida con el fin de efectuar un diagnóstico preimplantatorio. Se argumentó que no eran una pareja estéril.

Ante esta negativa, el matrimonio acudió al TEDH, denunciando que la normativa italiana era contraria al artículo 8 de la CEDH, que reconoce el derecho a la propia vida privada y familiar. Dicho artículo habría sido vulnerado por una injerencia ilegítima del Estado, en la medida en que prohíbe (artículos 1 y 4.1 de la Ley de 2004) acceder a la reproducción artificial a las parejas fértiles, que, no obstante, sean portadores de graves enfermedades transmisibles. ${ }^{24}$ Esta sentencia del alto Tribunal favorable el uso de la fertilización in vitro en situaciones como la descrita. Por tanto, hace necesario revisar el concepto mismo

\footnotetext{
${ }^{23}$ VIDAL MaRtinez, JaIme, "Acerca de la Sentencia del Tribunal Europeo de derechos Humanos. Caso S. H. y Otros contra Austria. TEDH 2010/56 de 1 de abril, en materia de reproducción humana asistida y su incidencia en el panorama legislativo europeo", Revista de derecho y genoma humano, No. 34, Madrid, 2011, p. 88.

${ }^{24}$ Berti de MarinI, GIovannI, "La jurisprudencia italiana en materia de reproducción asistida", Instituto de Derecho Iberoamericano. Disponible en: http://roderic.uv.es/handle/10550/43210
} 
de infertilidad, que no puede limitarse a englobar los casos en los que materialmente es imposible la procreación natural, sino también todas aquellos en los cuales la pareja, aun siendo biológicamente fértil, desde un punto de vista psicológico-moral, no se encuentra en condiciones prácticas de poder procrear.

Con los avances de la tecnología y su aplicación a la reproducción humana, el principio romano, que Paulo tomó del Digesto, mater semper certa est, ${ }^{25}$ que proclamaba indubitada la maternidad, se pone hoy en tela de juicio. Puede existir disociación entre concepción-gestación y parto. La mujer que da a luz puede ser simple portadora de la gestación, sin vínculo biológico con el nacido, si en su útero fue implantado un embrión obtenido en laboratorio con material genético de otra fémina. Así, ella no aporta sus propios óvulos, y puede existir una tercera mujer implicada en el nacimiento del nuevo ser, que sería aquella que tiene la voluntad de convertirse en madre pero no puede lograrlo naturalmente, pues no es apta para concebir ni gestar. Aparece así la diferencia entre portadora subrogada y madre subrogada o sustituta.

El uso de una portadora subrogada puede producirse en casos de mujeres cuyos ovarios tienen la capacidad de producir óvulos normalmente, pero son incapaces de llevar a término la gestación por defectos uterinos, malformaciones, problemas de capacidad o por afecciones limitantes para la vida de la madre o que pongan en peligro la vida del niño. La utilización de una madre subrogada puede producirse, por otra parte, en casos de incapacidad para proveer los componentes genéticos y gestacionales del embarazo. Es el caso de mujeres a quienes se les ha extirpado el útero y los ovarios, o cuando existe la posibilidad de que puedan trasmitir una enfermedad o defecto genético a su descendencia.

En caso de uniones homosexuales masculinas, también será necesaria la intervención de una mujer ajena a la pareja para concebir un hijo, aporte 0 no sus propios óvulos para combinarlos con el semen de unos de los hombres integrantes de dicha unión o de un tercero. Así, la mujer que aporta su propio óvulo y gesta en su vientre un hijo para otra u otro, en realidad ha procreado "por encargo", pero biológicamente tiene innegables vínculos con el nacido.

\footnotetext{
${ }^{25}$ En principio, la idea de maternidad no se asociaba a la palabra mater, pues ese título fue conferido a Minerva, Diana y Vesta, todas ellas reputadas diosas vírgenes. Por este motivo, dicho término sirvió para denominar a la mujer que vivia honestamente y conforme a las buenas costumbres, sin importar si era soltera, casada o viuda, nacida libre o liberta. Luego se asoció al nacimiento de hijos, que normalmente ocurría en el seno de la familia, traídos al mundo por la llamada mater familias, denominación que designaba a la esposa del pater familias, no con el objeto de conferirle el mismo estatus dentro del núcleo familiar, sino simplemente como indicativo de ser la cónyuge de aquél. Arámbula Reyes, Alma, La maternidad subrogada, México, Servicio de Investigación y Análisis - Cámara de Diputados, 2008, p. 10.
} 
Como afirma Graciela Medina, ${ }^{26}$ en doctrina se diferencia la situación de la mujer que lleva a cabo el embarazo con material genético de terceros, de la situación de la mujer que aporta su propio material genético y además lleva adelante el embarazo para otros. Ambos casos tienen en común que se pacta el llevar adelante un embarazo para entregar al niño a otros; se diferencian porque en la gestación por otro la mujer que lleva adelante el embarazo no aporta sus óvulos.

Así, la llamada maternidad subrogada puede adoptar diferentes supuestos:

- Pareja heterosexual que, aportando su material genético (óvulos femeninos y esperma masculino), necesita un vientre de otra mujer que geste el producto de la concepción lograda a través de la fecundación in vitro.

- Pareja heterosexual u homosexual en la que sólo uno de ellos aporta su material reproductor. La procreación es parcialmente heterónoma. La gestación se produce en el vientre de una mujer ajena a la pareja, que puede a su vez aportar o no sus propios óvulos.

- Pareja heterosexual u homosexual en la cual ninguno de los miembros aporta material genético. Los gametos con los que se realiza la fecundación son ajenos a la pareja, pudiendo aportar los óvulos la mujer que realiza la gestación u otra distinta.

- Persona sola, hombre o mujer, que, aportando o no su material genético, necesita la gestación de sustitución para el nacimiento del niño. Puede aportar los óvulos la mujer que realiza la gestación u otra distinta.

Como regla, a pesar del uso relativamente frecuente de la subrogación (parcial o plena), extendida hoy también a parejas del mismo sexo, casi ningún ordenamiento jurídico establece la ruptura del principio pauliano respecto a la maternidad. Se mantiene el hecho del parto como clave fundamental para su determinación.

Muchas legislaciones repudian este tipo de prácticas por considerar que se cosifica al niño y a la mujer. Así, las prohíben mediante normas civiles que declaran la nulidad del contrato y, en algunos casos, estableciendo normas penales que sancionan con prisión y multas su celebración. Los ordenamientos jurídicos que regulan estos contratos, casi siempre lo hacen en el marco de sus

\footnotetext{
${ }^{26}$ Medina, Graciela, Gestación por otro. De la ejecución forzada del convenio a la sanción penal. El turismo reproductivo. La situación en el derecho comparado, AR/DOC/4369/2012.
} 
leyes reguladoras de las técnicas de fecundación asistida. Lo admiten sólo en casos de contratos gratuitos o altruistas, aunque generalmente se establece la necesidad de que los comitentes asuman los gastos económicos del embarazo y el parto.

Allí donde el legislador rechaza la maternidad subrogada, se ha considerado como principio general que estos contratos están prohibidos por ser contrarios al orden público y a las buenas costumbres. Se dice que son, además, inmorales, porque atentan contra la dignidad de las mujeres, contra la libertad y la autonomía. No consienten libremente que su práctica implica una manipulación del cuerpo femenino y una forma de explotación; por tanto, implica una cosificación de la mujer en virtud de que la gestante se convierte en un mero "ambiente" o "incubadora humana" para el hijo de otro.

Además tendrían por objeto la entrega de un niño, ${ }^{27}$ lo cual constituye un objeto ilícito. Implica convertir al hijo en objeto de comercio, debido a que es atender más a los intereses de los futuros padres que a los del niño, y pretende convertir al niño en objeto de propiedad, en cuanto es algo de lo que se puede disponer y celebrar acuerdos al respecto. De celebrarse en contra de la prohibición legal, se considerarían absolutamente nulos. A pesar de ello, la sanción de nulidad del contrato deja sin resolver cuestiones medulares, especialmente las relativas a la filiación del niño, que han sido resueltas de diversos modos por la jurisprudencia.

Las cortes americanas han sido más proclives a la admisión de estos contratos, sobre todo cuando la gestación se lleva a cabo por una mujer que no aporta su material genético. Destaca el caso Jhonson $v$ s. Calvert, resuelto por la Suprema Corte de California en el año 1993. Este caso es considerado señero en esta sede por las consideraciones que se ofrecieron para admitir la validez del convenio. La Corte entendió que no es contrario al orden público el contrato de maternidad subrogada celebrado entre las partes por cuanto:

- Los pagos hechos en el contrato tenían como objetivo compensarla de sus servicios en gestar el niño y someterse a las labores de parto, antes que compensarla por renunciar a sus derechos de madre, respecto del niño.

- No se establece elemento de coacción alguno, ya que permite a las partes el aborto.

\footnotetext{
27 Sánchez Aristi, Rafael, "La gestación por sustitución: dilemas éticos y juridicos", Humanitas Humanidades Médicas, No. 49, Madrid, abril de 2010, p. 25.
} 
- No explota la condición de las mujeres de menos recursos en un grado mayor que las explota la necesidad económica en general, al inducirlas a aceptar empleos menos remunerados o que son desagradables por otras razones.

- No considera a los niños mercancías.

- Negar valor al contrato impide que la mujer gestante tenga la libertad personal de obtener un beneficio económico de la manera que lo desee.

- Estos contratos no afectan el interés del niño porque el interés de los niños tan pequeños coincide con el de los padres.

- La maternidad se establece no por el hecho del parto ni por la realidad genética sino por la intención. ${ }^{28}$

En sentido contrario, la nulidad de los convenios y de la adopción posterior fue establecida en el fallo plenario de la Corte de Casación Francesa en mayo de 1991. Anuló una sentencia de la Corte de París que había dado lugar a una adopción, particular que es repetido por la jurisprudencia posterior. En el caso resuelto por la Corte de Casación, la cónyuge de un matrimonio sufría una esterilidad absoluta que había motivado a su marido a donar su esperma a otra mujer. Esta última trajo al mundo un niño que fue reconocido como hijo natural de él y solicitado en adopción por su esposa, quien inició el proceso correspondiente. La Corte de París aceptó el proceso, tomando en cuenta el interés del menor, quien se había criado siempre en el hogar del matrimonio y valorando que el niño no tenía una filiación materna reconocida.

Los fundamentos dados en el fallo plenario de la Corte de Casación para anular la decisión de la Corte de París fueron los siguientes:

- La convención por la cual una mujer se compromete, aún a título gratuito, a gestar y traer al mundo un niño y abandonarlo a su nacimiento contraviene tanto el principio de orden público de la indisponibilidad del cuerpo humano, así como el de la indisponibilidad del estado de las personas.

- La adopción es la última fase de un convenio nulo que atenta al orden público y que por lo tanto en interés de la ley no puede ser aceptada. ${ }^{29}$

\footnotetext{
${ }^{28}$ Suprema Corte de California, Estados Unidos de América, 20/05/93, Johnson vs. Calvert, 1993, WL 167739, Comentado por Medina, Graclele, "Maternidad por sustitución - Principales cláusulas contractuales y soluciones en la jurisprudencia francesa y norteamericana", la Ley, 1997-C, 1433.

${ }^{29}$ Medina, Graciela, Gestación por otro. De la ejecución forzada del convenio a la sanción penal. El turismo reproductivo. La situación en el derecho comparado, AR/DOC/4369/2012, p. 8.
} 
Esta posición, mantenida posteriormente por otros fallos franceses y de otros países europeos, ha sido fustigada por el Tribunal Europeo de Derechos Humanos, con sede en Estrasburgo. El 26 de junio de 2014, el Tribunal Europeo de Derechos Humanos condenó a Francia por negarse a reconocer el vínculo de filiación entre unos niños nacidos a través de gestación subrogada en los Estados Unidos y sus padres y madres de intención, de nacionalidad francesa.

Dos matrimonios heterosexuales, los Mennesson y los Labassee, formularon la denuncia que derivó en dicha sentencia a su favor. Las hijas gemelas de los Mennesson nacieron en el año 2000, y en 2001 la pequeña de los Labasse. Desde entonces, hace más de una década, la administración francesa optó por no reconocer a sus padres como tales, considerando que hacerlo promovía una práctica ilegal que no se quería alentar.

El Tribunal de Estrasburgo condena esta "situación de incertidumbre jurídica” a la que Francia ha condenado a los bebés desde su nacimiento. Alega que se está atentando deliberadamente contra el derecho a la identidad de las menores. Aunque el padre en ambos casos denunciados era francés, las hijas aún no poseían la nacionalidad francesa. El Tribunal recriminó al país que si bien como Estado tiene libertad para decidir sobre la autorización o prohibición de la subrogación, las resoluciones violaban derechos legítimos de los niños, ya que la ilegalidad de una determinada técnica reproductiva en un país europeo no puede privar a los menores, nacidos en el extranjero con esta técnica e hijos de europeos, del reconocimiento de su filiación en los países de origen de sus padres.

El Tribunal Europeo de Derechos Humanos tiene pendientes tres casos similares denunciados por padres franceses. Los jueces de Estrasburgo también tienen sobre la mesa denuncias por el rechazo de Italia y Bélgica al procedimiento de las madres subrogadas.

\section{La procreación asistida y el interés superior del niño}

La noción actual de derechos humanos se erige sobre la idea central de considerar que todas las personas, incluidos los niños, gozan de los derechos, y que es deber de los Estados promover y garantizar su efectiva protección igualitaria. Así, el reconocimiento jurídico de la dignidad humana, el respeto a los atributos y cualidades intrínsecas de todas las personas, es la base para reconocer, en virtud del propio principio de igualdad, la existencia de protecciones jurídicas y derechos específicos de ciertos grupos de personas, ya sea porque en forma discriminatoria se les ha privado de protección, o bien porque circunstancias particulares de su vida dificultan el acceso o idoneidad de los mecanismos ordinarios de protección, entre los cuales están los niños. 
El principio del interés superior del menor, enarbolado por la Convención Internacional sobre los Derechos del Niño de $1989,{ }^{30}$ se integra por un conjunto de acciones y procesos tendientes a garantizar un desarrollo integral y una vida digna, así como las condiciones materiales y afectivas que permitan vivir plenamente y alcanzar el máximo de bienestar posible a niñas y niños.

Con este principio, se trata de garantizar el reconocimiento de los derechos humanos de las niñas y los niños, procurando que, antes de tomar una medida respecto a ellos, se adopten aquellas que promuevan y protejan sus derechos. Así se tratan de superar dos posiciones extremas: el autoritarismo o abuso de poder que ocurre cuando se toman decisiones referidas a los niños y niñas, por un lado, y el paternalismo, por otro.

Algunas técnicas de reproducción humana asistida han sido tildadas de violatorias del interés superior del niño, especialmente si se aplican a personas solas y parejas homoafectivas. En opinión de Zárate-Cuello y Celis, las familias homoparentales "crean nuevas dinámicas sociales que generan dilemas para la bioética y retos al bioderecho, puesto que estos nuevos modelos de familia transforman y amenazan a la familia nuclear". ${ }^{31}$ Señalan que debe reflexionarse en cuanto al:

alcance biojurídico de los hijos que han sido producto de las técnicas de procreación humana asistida, resaltando que la procreación homoparental se está convirtiendo en mera reproducción, donde se soslaya el parentesco de las relaciones biológicas, transformándolas en unas no biológicas, y pasando por encima de los lazos de sangre que determinan genéticamente aspectos preponderantes del inicio, desarrollo y final del ciclo vital del ser humano. Además, se pone como barricada a los hijos de estas parejas para que forzosamente sea aceptado el matrimonio homosexual, con el pretexto de defender el bien superior del niño sin que tenga la posibilidad de escoger el tipo de familia en la que nace. $^{32}$

\footnotetext{
${ }^{30}$ También aparecen referencias a este principio en la Declaración de los Derechos del Niño de 1959 y en la Convención sobre la eliminación de todas las formas de discriminación contra la mujer, entre otros documentos internacionales.

${ }^{31}$ Zárate-Cuello, Amparo y Cells, Luis Gustavo, "Implicaciones bioéticas derivadas del acceso de las parejas del mismo sexo a las tecnologías provenientes de la biomedicina y la biotecnología, para la conformación de familias homoparentales", Revista Persona y Bioética, vol. 19, No. 1, 2015 p. 48.

32 Zárate-Cuello, Amparo y Celis, Luis Gustavo, "Implicaciones bioéticas derivadas del acceso de las parejas del mismo sexo a las tecnologías provenientes de la biomedicina y la biotecnología, para la conformación de familias homoparentales", Revista Persona y Bioética, vol. 19, No. 1, 2015.
} 
El mito de que sólo son "naturales" las familias clásicas (constituidas en torno al matrimonio heterosexual y su prole) esgrime sus lanzas contra nuevas formas familiares. Argumenta que no es favorable al niño desarrollar su personalidad en ausencia de las figuras del padre o la madre, o en convivencia con dos madres o dos padres unidos en relación homosexual, permitida o no por las leyes. Como afirman Herrera y de la Torre, esta posición oculta "una tríada común conocida como sistema de género conformada por una visión lineal que supone la concordancia entre el sexo biológico/genético, la identidad de género y la orientación sexual, de la cual se desprende, a su vez, una visión unívoca y normativa de lo que debe entenderse por familia". ${ }^{33}$

Cuando las mujeres solas desean concebir un hijo haciendo uso de las tecnologías reproductivas asistenciales, la cuestión se torna polémica. El reconocimiento y la protección de los derechos reproductivos de todas las personas debe conllevar la aceptación de esta práctica. A ello se suma que tampoco debe ser un impedimento en estos casos el interés superior del niño. El hijo, en este caso, no será resultado de una obligación inherente a la institución matrimonial o un débito de pareja, sino fruto del deseo de la mujer que asume la maternidad con amor y responsabilidad, lo que redundará en beneficio del menor. La maternidad de una mujer sola no debe estar vinculada a las exigencias o el capricho de un hombre, ni a situaciones plagadas de vejaciones y humillaciones.

Si la sociedad de nuestros tiempos acepta la maternidad natural de mujeres sin pareja masculina, nada obsta la aceptación también de la maternidad sin apareamiento sexual. Como afirma Coll de Pestaña, "esta mujer [sola] quiere tener un hijo porque ansía quererlo, porque quiere acunarlo, educarlo y protegerlo, que es lo que se pretende que se haga con los niños". ${ }^{34}$ La maternidad, en estos supuestos, se afianza en la voluntad procreacional, asumiendo con responsabilidad su alcance afectivo, cultural y social. Las mujeres que de acuerdo con su orientación sexual viven en parejas homoafectivas, también podrían acceder a las técnicas de reproducción humana asistida, con semen de donante, aportando una de ellas sus propios óvulos o con material genético de otra, pero llevando adelante gestación y el parto.

Del mismo modo, un hombre solo estará en condiciones de ser padre haciendo uso de su autonomía procreacional, disociada del sexo. En este supues-

\footnotetext{
${ }^{33}$ Herrera, Marisa y de la Torre, Natalia, "La identidad trans frente a la performatividad reinante de los roles familiares", en Nora LLoveras, y Marisa Herrera (dirs.), El derecho de familia en Latinoamerica. Las familias y los desafíos sociales, volumen 2, Nuevo Enfoque Jurídico, Córdova, Argentina, 2012, p. 685.

${ }^{34}$ Coll de Pestaña, Ivetre, "Análisis crítico sobre los efectos del desafío genético en el bienestar de los niños", Memorias del XII Congreso Internacional de Derecho de Familia, La Habana, Minjus, 2002, p. 160.
} 
to, la única vía para lograr un hijo biológico sería acudir a la maternidad subrogada, con los inconvenientes ya apuntados. Lo mismo ocurriría con las parejas homoafectivas masculinas. A mi juicio, si tales parejas pueden ofrecer un hogar con amor y responsabilidad a los niños concebidos de este modo, particular que deberá evaluarse adecuadamente en cada caso, ello no afectaría el interés del menor y no se cercenaría el derecho a reproducirse de los homosexuales.

Con base en este principio, se ha pretendido rechazar la práctica de la maternidad subrogada. Se alega que su uso "cosifica" al menor, lo convierte en objeto de un contrato, lo cual atenta contra su dignidad humana. Empero, los contratos de gestación por sustitución no tienen por objeto al niño en sí, sino únicamente la prestación del servicio de gestar y alumbrar, atendiendo a la capacidad o aptitud de la madre portadora. Se trata, claro está, de una prestación muy particular, que pone en tela de juicio la moral dominante a la que repugna el comercio con el cuerpo humano. Sin embargo, más allá de consideraciones éticas, si efectivamente se realiza, nace un niño que es persona, titular de los derechos humanos inherentes, que debe ser protegido y gozar de igual consideración que los menores que llegan al mundo a través de la concepción natural o mediante otras técnicas de reproducción asistida. ${ }^{35}$

\section{Epílogo}

Aunque los intereses de la ciencia y de la humanidad son de un valor inestimable, no pueden prevalecer sobre la libertad y los derechos de las personas. Por ello, los Estados, al dictar normas que regulen el uso de algunas técnicas de reproducción humana asistida deben velar porque no exista interferencia entre ambos. Al determinar quiénes serán los destinatarios de estas técnicas, es necesario colocar en un primer plano el interés superior del niño que va a nacer, aunque en algún sentido se prive a determinado grupo de personas del derecho a procrear mediante el uso de las TRHA, pues la ley civil deberá prohibir, en aras del orden público, lo que no puede tolerar sin ocasionar daños más graves.

El derecho a la vida es el supuesto ontológico de todos los demás derechos. Como derecho inherente a la personalidad, se reconoce por igual a toda persona por el solo hecho de serlo. Antes del nacimiento, el producto de la concepción es un valioso bien jurídico merecedor de tutela y protección; pero no es persona ni titular de los derechos que acompañan y llenan la personalidad jurídica.

\footnotetext{
${ }^{35}$ Valdés Diaz, Caridad del Carmen, "La maternidad subrogada y los derechos de los menores nacidos mediante el uso de esa técnica", en Leonardo Pérez Gallardo, Carlos Villabella Armengol y Germán Molina Carrillo (coords.), Derecho Familiar Constitucional, México, Mariel, 2016, p. 484.
} 
Los derechos sexuales y reproductivos deben reconocerse también a todas las personas, garantizando su ejercicio a través de políticas públicas efectivas, diseñadas sobre criterios de justicia distributiva y teniendo como base los principios éticos de autonomía, igualdad, diversidad, en comunión con el ejercicio de los derechos inherentes a la personalidad. Empero, los derechos sexuales y reproductivos deben ejercitarse con plena responsabilidad, porque en su ejercicio hay un límite natural que es el propio resultado de su práctica: la procreación de nuevos seres humanos.

En el caso particular de la gestación por sustitución, pienso que su aplicación no siempre viola el interés superior del niño, debido a que nace en una familia que lo deseó y no hubiera existido de no haberse recurrido a esa práctica. Por el contrario, el interés superior del niño exige la regularización de la gestación por sustitución, es decir, de un marco legal que lo proteja y le brinde seguridad jurídica.

Las técnicas de reproducción humana asistida abren una brecha de posibilidades a las personas que anhelan tener un hijo, pero al propio tiempo dan lugar a múltiples interrogantes jurídicas no siempre bien resueltas. No hay una única respuesta ni se trata de un tema puramente legal; está matizado por la filosofía de vida, la moral, la política y la religión. La sabiduría, como ya exponía Aristóteles, estará en normas que logren ubicarse en el punto medio, que busquen un justo equilibrio entre la exigencia de reconocer el mayor margen posible a la libertad para procrear y la de evitar poner en peligro los intereses del nacido y los de los terceros que resulten implicados.

Crónica: El día que nació el hijo y la madre portadora lo puso en sus brazos, fue el más feliz de sus vidas. Había llegado el fruto anhelado. Después de larga travesía, comenzaba la tarea de cuidar, proteger, educar, formar, proveer. Carga pesada, pero dichosa. La recompensa sería verlo crecer sano, fuerte, alegre. Cuando fuera un hombre de bien, repasarian todo el periodo de aquella vida anunciada.

\section{Bibliografía}

Arámbula Reyes, Alma, La maternidad subrogada, México, Servicio de Investigación y Análisis - Cámara de Diputados, 2008.

Berti de Marini, Giovanni, "La jurisprudencia italiana en materia de reproducción asistida”, Instituto de Derecho Iberoamericano. Disponible en: http://roderic. uv.es/handle/10550/43210

Bonllua Sánchez, Juan José, Personas y derechos de la personalidad, Madrid, Reus, 2010. 
CÁrcaba Fernández, María, Los problemas jurídicos planteados por las nuevas técnicas de procreación humana, Barcelona, José María Bosch, 1995.

Castiella Rodríguez, José, "La persona, el estado civil y el registro civil. Primera Parte. La persona en general”, en Juan Delgado de Miguel (coord.), Instituciones de derecho privado, tomo I, vol. 2, Madrid, Civitas, 2003.

Chía, Eduardo y Contreras, Pablo, “Análisis de la sentencia Artavia Murillo y otros (fecundación In Vitro) vs. Costa Rica de la Corte Interamericana de Derechos Humanos", Estudios Constitucionales, vol. 12, No. 1, Santiago de Chile, 2014. Disponible en http://dx.doi.org/10.4067/S0718-52002014000100015

CIDH, “Artavia Murrillo y otros vs. Costa Rica”. Disponible en: http://www.corteidh. or.cr/docs/casos/articulos/seriec_257_esp.pdf

Clemente Díaz, Tirso, Derecho Civil, tomo I, La Habana, enPes, 1983.

Coll de Pestaña, Ivette, "Análisis crítico sobre los efectos del desafío genético en el bienestar de los niños”, Memorias del XII Congreso Internacional de Derecho de Familia, La Habana, Minjus, 2002.

Giberti, Eva, Barrios, Gloria, Pachuk, Carlos, Los hijos de la fertilización asistida, Buenos Aires, Sudamericana, 2001.

Guzmán Ávalos, AniBal, Inseminación artificial y fecundación in vitro humanas. Un nuevo modo de filiación, México, Biblioteca Universidad Veracruzana, 2001.

Herrera, Marisa y de la Torre, Natalia, "La identidad trans frente a la performatividad reinante de los roles familiares”, en Nora LLoveras, y Marisa Herrera (dirs.), El derecho de familia en Latinoamerica. Las familias y los desafios sociales, volumen 2, Nuevo Enfoque Jurídico, Córdova, Argentina, 2012.

Kemelmajer de Carlucci, Aíd, El derecho humano a la vida intima de la mujer embarazada, el riesgo grave para su salud y el principio de igualdad frente a los casos de no punibilidad en la jurisprudencia del Tribunal Europeo de Derechos Humanos, Argentina, Fondo Editorial La Ley - Academia Nacional de Derecho y Ciencias Sociales de Buenos Aires, 2007.

Mateo de Acosta, Osvaldo y Andino Valdés, Nidia, "Fertilización in vitro (Fiv) y transferencia de embriones (TE) en el humano. Consideraciones éticas, científicas y utilidad", Revista Cubana Médica, No. 24, agosto, 1985.

Medina, Graciela, Gestación por otro. De la ejecución forzada del convenio a la sanción penal. El turismo reproductivo. La situación en el derecho comparado, AR/DOC/4369/2012.

MinYERSKY, NeLly, “Derechos sexuales y reproductivos: el aborto legal y seguro”, en Aída Kemelmajer de Carlucci y Leonardo B. Pérez Gallardo (coords.), Nuevos perfiles del derecho de familia, Buenos Aires, Rubinzal Culzoni, 2006.

Planiol, Marcel, Tratado elemental de derecho civil, vol. III, México, Cajica, 1946.

SÁnchez ARISTI, RAFAeL, "La gestación por sustitución: dilemas éticos y jurídicos", $\mathrm{Hu}$ manitas Humanidades Médicas, No. 49, Madrid, abril de 2010.

Suprema Corte de California, Estados Unidos de América, 20/05/93, Johnson vs. Calvert, 1993, WL 167739, Comentado por Medina, Graciela, "Maternidad por susti- 
tución - Principales cláusulas contractuales y soluciones en la jurisprudencia francesa y norteamericana”, la Ley, 1997-C, 1433.

Valdés Díaz, Caridad del Carmen, "Del derecho a la vida y los derechos sexuales y reproductivos, ¿configuración armónica o lucha de contrarios?”, Ius, Revista del Instituto de Ciencias Jurídicas de Puebla, nueva época, año 5, julio-diciembre 2012.

Valdés Díaz, Caridad del Carmen, "La maternidad subrogada y los derechos de los menores nacidos mediante el uso de esa técnica”, en Leonardo Pérez Gallardo, Carlos Villabella Armengol y Germán Molina Carrillo (coords.), Derecho Familiar Constitucional, México, Mariel, 2016.

Vela SÁnchez, Antonio, Las familias monoparentales, Granada, Comares, 2005.

Vidal Martínez, Jaime, "Acerca de la Sentencia del Tribunal Europeo de derechos Humanos. Caso S. H. y Otros contra Austria. TEDH 2010/56 de 1 de abril, en materia de reproducción humana asistida y su incidencia en el panorama legislativo europeo", Revista de derecho y genoma humano, No. 34, Madrid, 2011.

ZÁrate Cuello, Amparo, Biomedicina y biotecnología ante la violencia prenatal (Legislación comparada con el derecho español), Colombia, Lid Editorial Colombia SAS - Ediciones de la U, 2014.

Zárate-Cuello, Amparo y Celis, Luis Gustavo, "Implicaciones bioéticas derivadas del acceso de las parejas del mismo sexo a las tecnologías provenientes de la biomedicina y la biotecnología, para la conformación de familias homoparentales”, Revista Persona y Bioética, vol. 19, No. 1, 2015. 